\title{
Fourier Transformation Infrared Spectroscopic Studies of Acidity of NaH-13 X Zeolites
}

\author{
Shatha Abd-Alhameed Al. Sofy \\ Institute of Technology, Middle Technical University \\ Baghdad, IRAQ \\ shathaalsofy@yahoo.com \\ Received: 19-March-2017 Revised: 06-May-2018 Accepted: 27-June-2018
}

http://doi.org/10.29194/NJES.21030428

\begin{abstract}
Fourier transformation Infrared spectroscopy (FTIR) has been used to characterize and measure the concentration of acid sites (Si-OH-Al groups) in NaH-13 X Zeolites. Ion exchange was followed by dealumination to get $(28,40,65,85.8$ and 97.5 Wt. \%) of NaH-13 X Zeolites samples. The conclusion of homogeneity of $\mathrm{OH}$ groups was obtained by analysis of Fourier transformation infrared spectroscopy absorption bands of $\mathrm{OH}$ groups after adsorption and desorption of Ammonia. It found that there were different acid sites on a broader absorption $\left(3,800-3,000 \mathrm{~cm}^{-1}\right)$ corresponds to hydroxyl groups of the less acidic Brønsted acid sites approximately at $3464 \mathrm{~cm}^{-1}$ and the more acidic at $3441 \mathrm{~cm}^{-1}$ and Lewis acid sites was found at $1636 \mathrm{~cm}^{-1}$ which is few and weak acid sites .It can be conclusion that concentrations of $\mathrm{OH}$ groups increased with increasing the exchange degree and delamination. The concentration of acid sites in samples were calculated from stretching frequencies and extinction coefficients of $\mathrm{OH}$ bands, also the frequency shift $\Delta v_{\mathrm{OH}}=23 \mathrm{~cm}^{-1}$ which was due to the hydrogen bonding of $\mathrm{OH}$ groups with ammonia in $97.5 \% \mathrm{NaH}-13 \mathrm{X}$ Zeolites. Knowing the acidity of catalyst is important for the reactions which required acidic surface.
\end{abstract}

Keywords: Brønsted Acidity, FTIR, Ammonia Adsorption, Acidity of Zeolites.

\section{Introduction}

Zeolites and other microporous materials are used as catalyst supports and as catalysts [1]. However, because of a number of desirable properties, Zeolites are used widely as catalysts in petrochemical industry ,these properties are: (1) presence of Brønsted acid sites (BAS) that act as active sites in catalysis (2) they have crystalline structures with the pores (channels) of molecular dimensions, and (3) high thermal stability. Also there are a large number of existing structures for Zeolites which allows selection of the suitable channels for particular target molecules and reactions. Only smaller molecules than zeolite channels can move through the channels and react (reactants) or escape (products).The shapeselectivity of molecules in the Zeolite catalysts make it very important in the exploitation of the industrial processes [2]. Faujasitic zeolites have channels of about $8 \AA$ diameter connecting by $13 \AA$ diameter (super cages) in three dimensional networks [3]. There are $\mathrm{Si}-\mathrm{OH}$ groups (silanols) in Zeolites which can occur at the external surface of crystals and may be occur at intra crystalline lattice defects which may influence catalytic phenomena [1].The Brønsted acidity in zeolites (aluminosilicates) is due to $\mathrm{OH}$ bridged between $\mathrm{Si}$ and $\mathrm{Al}$ of the framework. The acidity of zeolites governs their activity, that make many studies of the acidity, the strength of the acidic sites, determination of the nature and the number of acid sites. Among the main methods used, Fourier transformation infrared spectroscopy (FTIR) appears very fruitful [4].The infrared spectrum of a simple molecule arises as a result of the vibrations of the atoms within the molecule, the symmetry and bond strengths of the molecule as a whole determine the number and frequencies of the vibrations. When a simple molecule is adsorbed the "one-sided" surface forces exerted by a catalytic material must cause a change in asymmetry of the molecule, any quantities measure of this change can be directly related to the nature of the adsorption [5]. Beran and Schröder et al. [5] have proved the acid strength of bridging $\mathrm{Si}-\mathrm{OH}-\mathrm{Al}$ groups depends on, first the geometrical factor and secondly on the chemical factor also Datka and Gil [5] were studied heterogeneity of $\mathrm{OH}$ groups in faujasites .They found that the Si-OH-Al groups were homogeneous in Na-HX zeolite and heterogeneous in Na-HY zeolite from experiments of pyridine sorption and desorption, also they proved that in the case of Na-H-X zeolites only one band at $3478 \mathrm{~cm}^{-1}\left(\Delta v=182 \mathrm{~cm}^{-}\right.$ $\left.{ }^{1}\right)$ is present, whereas three sub maxima at 3320,3380 and $3420 \mathrm{~cm}^{-1}$ exist in Na-HY. The acid properties of Na-HX were modified by varying the $\mathrm{Na} / \mathrm{H}$ exchange degree, partial dehydroxylation, and by delamination. The acidity of $\mathrm{Na}-\mathrm{H}$-mordenites was studied by numerous authors using infrared spectroscopy, Temperature Programmed Desorption (TPD) of Ammonia microcalorimetry, and adsorption isotherms. Known zeolites contain either homogeneous, weakly acidic hydroxyls (Na-HA, 
$\mathrm{Na}-\mathrm{HX}$ ) or more acidic but heterogeneous ones (HZSM-5, HY, H-Beta, H-mordenite). No zeolite is known with strongly acidic homogeneous $\mathrm{OH}$ groups [6]. The micro calorimetric studies of ammonia adsorption suggested homogeneity of (Na-HA, Na-HX): the adsorption heat was constant until all the $\mathrm{OH}$ groups were neutralized [7]. Ammonia has been used as a probe molecule in infrared spectroscopy. The intensity of $\mathrm{OH}$ depends on the concentration of $\mathrm{OH}$ and the extinction coefficient [8]. Na-H-13X may contain both Brønsted and Lewis acid sites, practically all studies were made using pyridine as the probe molecule. But pyridine cannot reach acid sites in narrow channels. Ammonia can penetrate all zeolite pores and provides information on the whole population of acid sites which some of them may be located in broad channels and others in narrow ones. In the present work the acid properties of $\mathrm{Na}-\mathrm{H}-13 \mathrm{X}$ Zeolite were determined by Fourier transformation infrared spectroscopy techniques of ammonia sorption. Masato et. al. [9], studied the adsorption of $\mathrm{NH}_{3}$ molecules and $\mathrm{NH}_{4}{ }^{+}$on ZSM-5 zeolites with different $\mathrm{SiO} / \mathrm{Al}_{2} \mathrm{O}_{3}$ ratios by near and middle infrared spectroscopy and they concluded that the adsorption of $\mathrm{NH}_{3}$ molecules and $\mathrm{NH}_{4}{ }^{+}$on ZSM-5 zeolites were successfully investigated. To prevent side reactions, it must be decrease the acidity of the catalyst and decrease the reaction temperature [10]. Dealumination causes an increase in the acid strength [11]. Shashikant and Mariya [12], determined the concentration of Lewis and Brønsted acid sites of H-MFI Zeolites after adsorption of pyridine by FTIR spectroscopy. They studied the influence of the reaction conditions and zeolite characteristics on bioethanol dehydration pathways. Ammonium and protonic zeolite forms are studied by Paola and Katina; they found a linear relationship between rate constant in the etherification of HMF (5Hydroxymethyl furfural) and the amount of Lewis acid sites and Brønsted acid sites [13]. Ying Li et al. studied the influence of Brønsted acid density and strength on the stability of H-MOR in Dimethyl ether carbonylation; they recognized Pyridine adsorption is as an efficient technique to improve stability by FTIR. They concluded that acidity strongly influences the activity and stability of modified MOR, also the stability is affected by the amount and location of acid site [14].

Acidity of zeolites must be taken into account in reactions, to prevent side reactions, it is usual to decrease the acidity of the solids and the reaction temperature. In order to solve these problems regarding the acidity (strength, number) some samples of dealuminated $13 \mathrm{X}$-zeolites were prepared with different acidities and tested. The aim of this study was to determine the concentration of Brønsted and Lewis acid sites in Na-H-13X Zeolites and their acid strength using quantitative FTIR experiments of ammonia adsorption, to prove that acidic hydroxyls $(\mathrm{OH})$ in Na-H-13X Zeolites are homogeneous. Known homogeneous zeolites are weakly acidic, also to find the relation between the concentration of acidic hydroxyls and the $\mathrm{Na} / \mathrm{H}$ exchange degrees.

\section{Experimental work}

A commercially available sodium zeolites from Fluka Company AG as synthetic crystalline zeolite type $\mathrm{Na}-13 \mathrm{X}$ with formula composition $\mathrm{Ca}_{4.5}$. $\mathrm{Na}\left(\mathrm{AlO}_{2}\right)_{12} \cdot\left(\mathrm{SiO}_{2}\right)_{12} .30 \mathrm{H}_{2} \mathrm{O} \quad(\mathrm{Si} / \mathrm{Al}=1.75)$ was used as the original zeolite table (1). Ionicexchanged by $\mathrm{NH}_{4} \mathrm{Cl}(2 \mathrm{~N})$ solution for (2h.) two times at $80^{\circ} \mathrm{C}$ was used to prepare $\mathrm{H}-13 \mathrm{X}$ Zeolites. To dealuminate the exchanged zeolites different molarities $(0.2,0.3,0.5$ and $4 \mathrm{~N})$ of hydrochloric acid (Merck) at $80^{\circ} \mathrm{C}$ were used. The exchange degrees of our samples were $(28,40$, 65, 85.8 and 97.5 Wt. \%) (determined by Chemical analysis in the company of Geological Survey and mining) has shown in Table (2). The Fourier transformation infrared spectroscopy was taken by (FTIR-8400S-Shimadzo) spectrometer with a resolution of $2 \mathrm{~cm}^{-1}$. The percentage of the sample in the $\mathrm{KBr}$ salt was $2-5 \%$. The samples were pressed into thin wafers $\left(5-10 \mathrm{mg}^{\left.-\mathrm{cm}^{-2}\right)}\right.$ and directly activated in situ in an I.R. cell at $523 \mathrm{~K}$ for 3 hours in a vacuum $\left(1.10^{-3} \mathrm{mg} . \mathrm{cm}^{-2}\right)$ then pretreated by small measured portions of dry ammonia (Linde Carbide 99.97\%) at $320 \mathrm{~K}$ in Na-H-13X Zeolites (exchange degree 97.5\%), then by an access of ammonia ( the amounts of ammonia added must be larger than the amounts needed to saturate all of the acid sites) after 30 min. contact with the zeolites, in the evacuated cell. Physically adsorbed ammonia were removed by evacuation at $523 \mathrm{~K}$ again for 3hours, only chemisorbed ammonia will remain, each ammonia molecule reacts chemically with one acid site (desorption of physically adsorbed ammonia occurs in the range of $473 \mathrm{~K}-523 \mathrm{~K}$ ).

Table (1): Chemical composition and oxide formula for $\mathrm{Na}-13 \mathrm{X}$ zeolite.

\begin{tabular}{|c|c|}
\hline $\begin{array}{c}\text { Na-13X } \\
\text { Zeolite }\end{array}$ & Chemical Composition Wt. \% \\
\hline $\begin{array}{c}\text { oxide } \\
\text { formula }\end{array}$ & $\mathrm{Ca}_{4.5} \cdot \mathrm{Na}\left(\mathrm{AlO}_{2}\right)_{12} \cdot\left(\mathrm{SiO}_{2}\right)_{12} .30 \mathrm{H}_{2} \mathrm{O}$ \\
\hline $\mathrm{SiO}_{2}$ & 37.0 \\
\hline $\mathrm{Al}_{2} \mathrm{O}_{3}$ & 36.21 \\
\hline $\mathrm{Na}_{2} \mathrm{O}$ & 10.3 \\
\hline
\end{tabular}


Table (2): Ion exchange data for zeolites $13-\mathrm{X}$ after treatment with $\mathrm{NH}_{4} \mathrm{Cl}$ and after

\begin{tabular}{|c|c|c|c|c|c|c|}
\hline 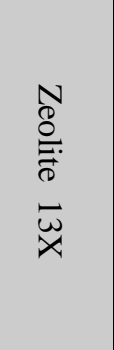 & 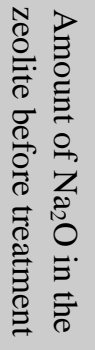 & 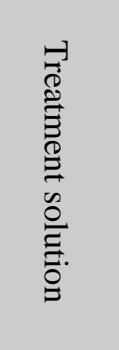 & 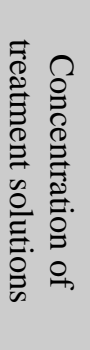 & 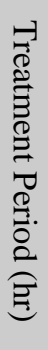 & 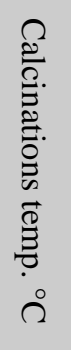 & 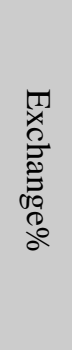 \\
\hline $\mathrm{NH}_{4}-\mathrm{X}$ & 10.3 & $\mathrm{NH}_{4} \mathrm{Cl}$ & $2 \mathrm{~N}$ & 4 & 550 & 28 \\
\hline $\mathrm{H}-\mathrm{X}$ & & $\mathrm{HCl}$ & $0.2 \mathrm{~N}$ & 3 & 550 & 40 \\
\hline $\mathrm{H}-\mathrm{X}$ & & $\mathrm{HCl}$ & $0.3 \mathrm{~N}$ & 3 & 550 & 65 \\
\hline $\mathrm{H}-\mathrm{X}$ & & $\mathrm{HCl}$ & $0.5 \mathrm{~N}$ & 3 & 550 & 85.8 \\
\hline $\mathrm{H}-\mathrm{X}$ & & $\mathrm{HCl}$ & $4 \mathrm{~N}$ & 3 & 550 & 97.5 \\
\hline
\end{tabular}

\section{Results and Discussion}

\subsection{OH groups in Na-H-13X Zeolites}

The FTIR spectrum of 13-X zeolite $(\mathrm{Si} / \mathrm{Al}=1.75)$ before any treatment and before adsorption of ammonia is presented in (Fig.1). One distinct $\mathrm{Si}-\mathrm{OH}-\mathrm{Al}$ band at $3474 \mathrm{~cm}^{-1}$ which can be Brønsted acid sites can be noticed.

In Figure (2), one band appeared at $3464 \mathrm{~cm}^{-1}$ characteristic of ammonia bonded to $\mathrm{Na}^{+}$cations $\left(\mathrm{NaNH}_{3}\right)$. The spectra of (Si-OH-Al groups) can be noticed in Figures (3), (4), (5), (6) and (7) which become shifted to lower frequencies because of hydrogen bonded with ammonia which adsorbed at $320 \mathrm{~K}$ in $\mathrm{Na}-\mathrm{H}-13 \mathrm{X}$ Zeolites. Also one I.R. band is shown at $1636 \mathrm{~cm}^{-1}$ which is the characteristic of ammonia bonded with Lewis acid sites $\left(\mathrm{LNH}_{3}\right)$.

It can be noticed that before ammonia adsorption, and after the reaction of ammonia with Lewis acid sites, there are no change happened for $1636 \mathrm{~cm}^{-1}$ band. That is mean Lewis acid sites $\left(\mathrm{LNH}_{3}\right)$ are very weak in $\mathrm{Na}-\mathrm{H}-13 \mathrm{X}$, $1636 \mathrm{~cm}^{-1}$ band has low intensities and cannot be distinguished.

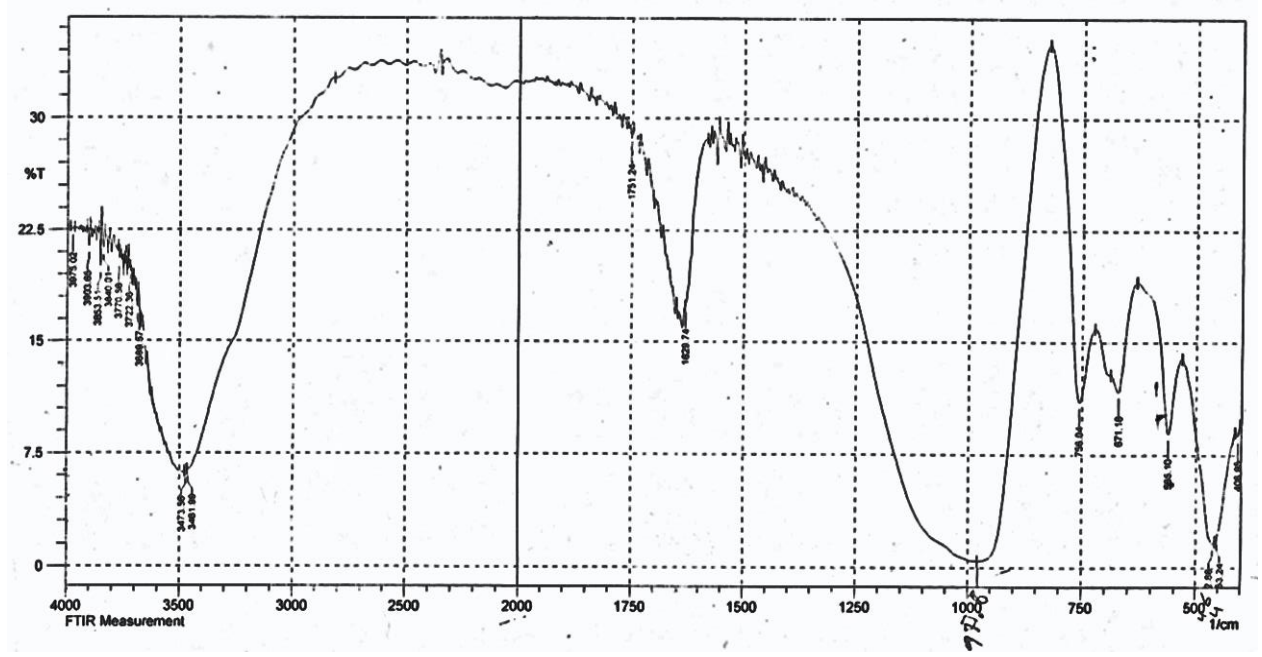

Figure (1): FTIR Spectrum of free $\mathrm{Si}-\mathrm{OH}-\mathrm{Al}$ groups in $\mathrm{Na} 13 \mathrm{X}$ zeolite $(\mathrm{Si} / \mathrm{Al}=1.75)$ before any treatments.

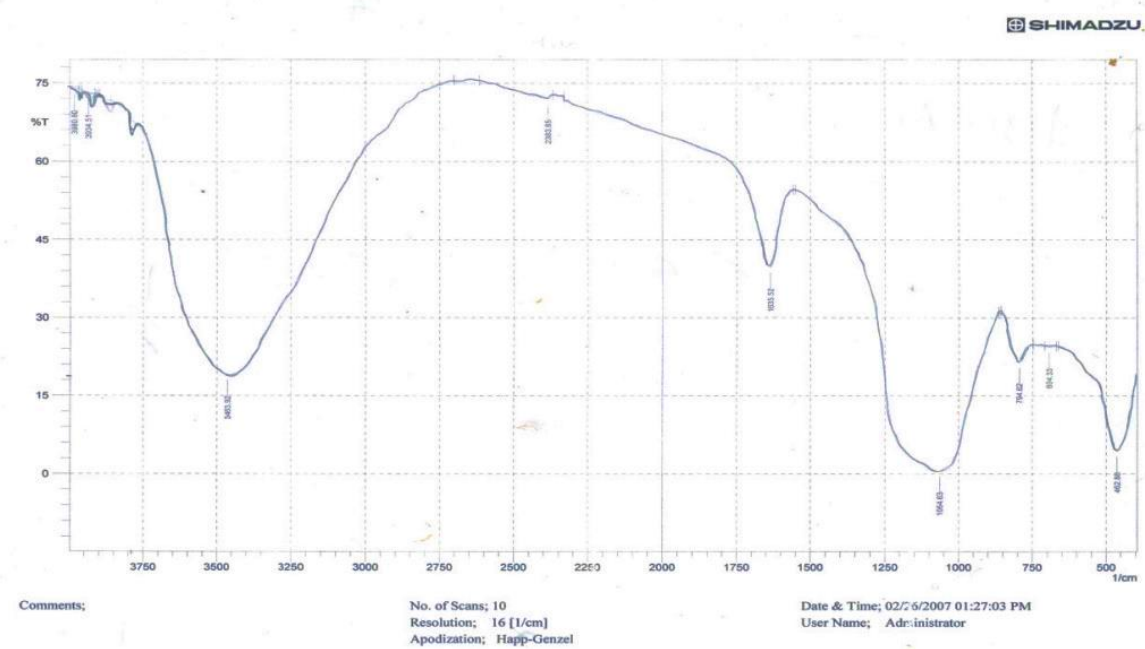

Figure (2): FTIR Spectrum of OH groups in NaH13X zeolites (28\%) after Ammonia adsorption. 


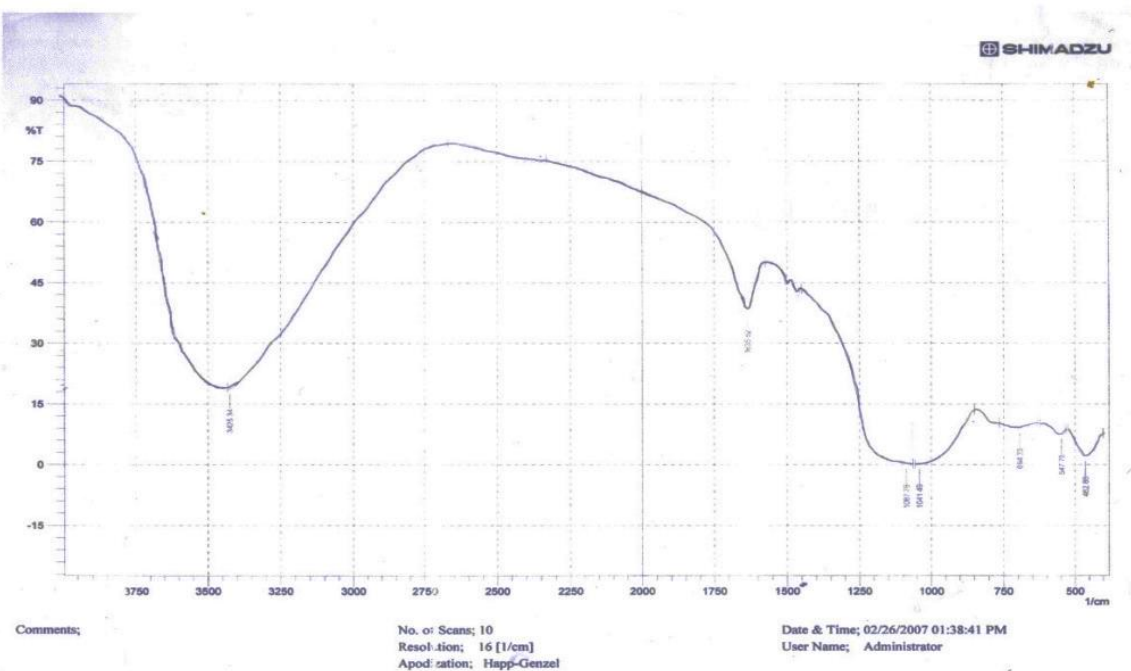

Figure (3): FTIR Spectrum of OH groups in NaH13X zeolites (40\%) after Ammonia adsorption.

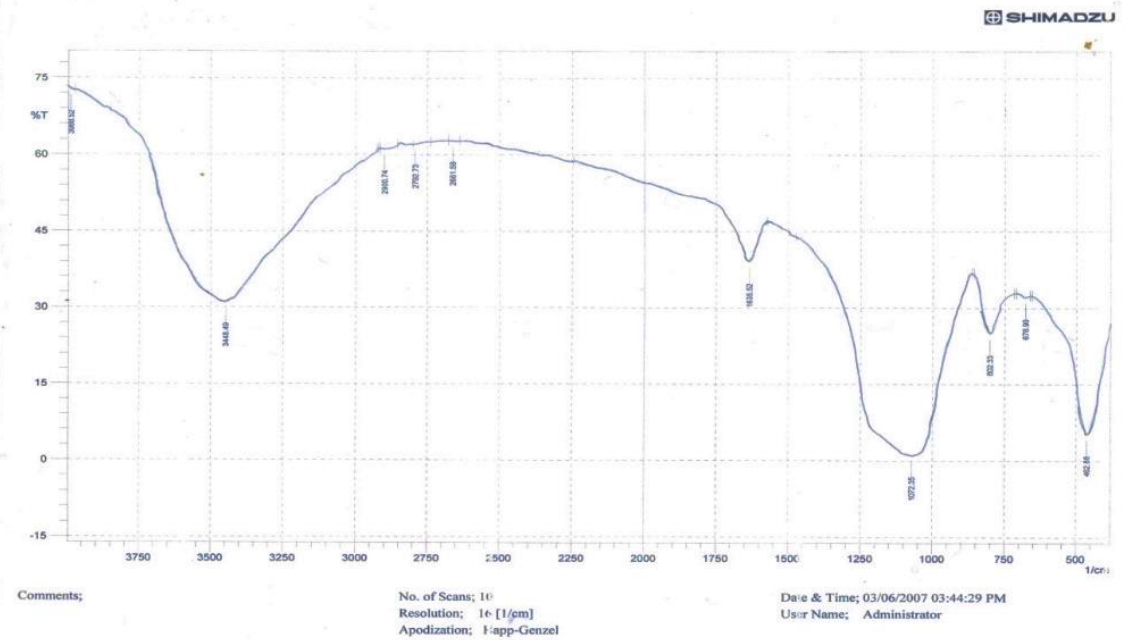

Figure (4): FTIR Spectrum of OH groups in NaH13X zeolites (65\%) after Ammonia adsorption

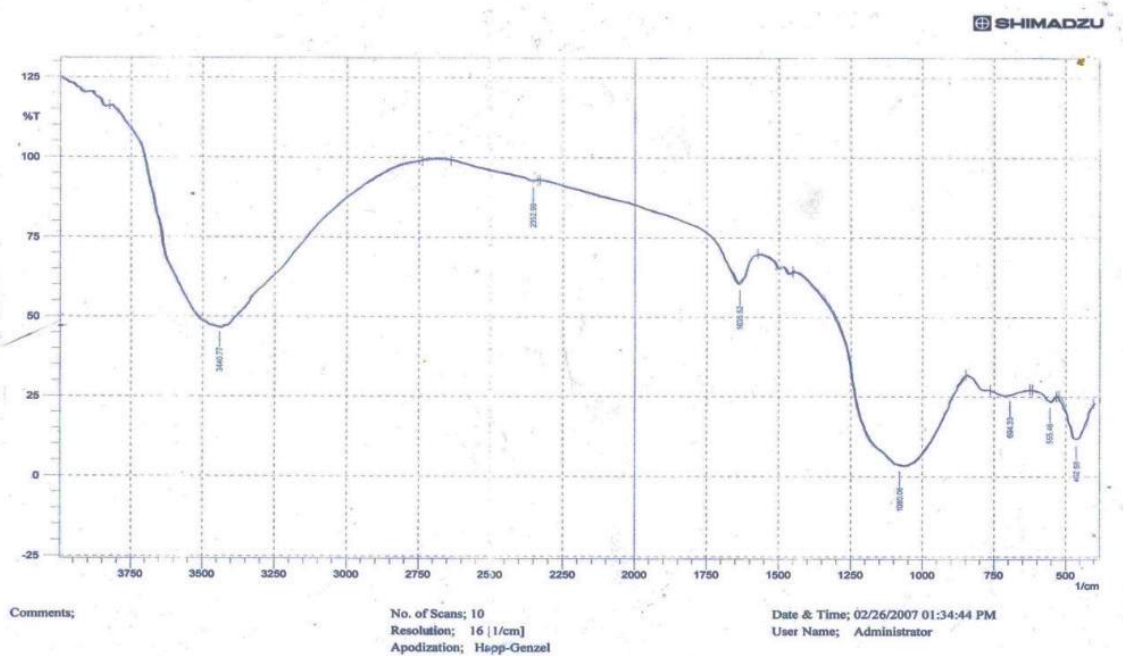

Figure (5): FTIR Spectrum of OH groups in NaH13X zeolites (85.8\%) after Ammonia adsorption. 


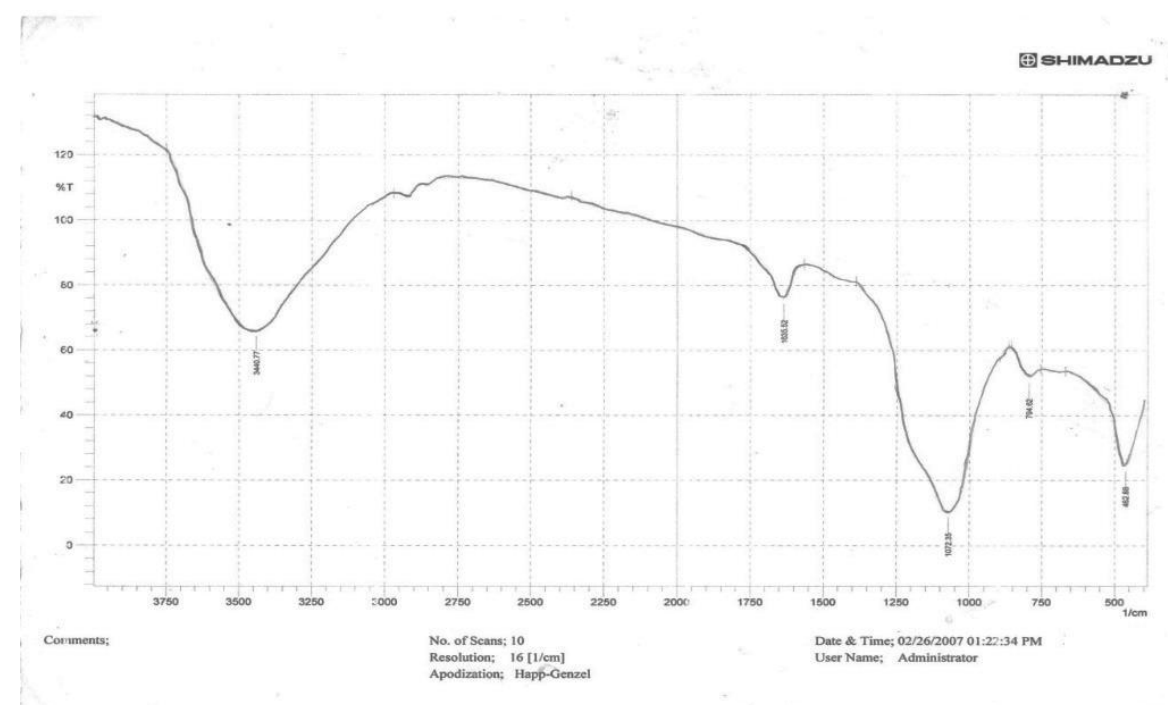

Figure (6): FTIR Spectrum of $\mathrm{OH}$ groups in NaH13X zeolites $(97.5 \%)(\mathrm{Si} / \mathrm{Al}=52)$ after Ammonia adsorbtion.

Figure (7) shows the relation between the amount of chemisorbed ammonia and the intensity of $\mathrm{NH}_{4}^{+}$at $1450 \mathrm{~cm}^{-1}$ band, small portions of ammonia were adsorbed at $320 \mathrm{~K}$ in Na-H13X (exchange degree $97.5 \%$ ) until all hydroxyls were neutralized (when the $\mathrm{OH}$ band disappeared), practically the intensity of the $1450 \mathrm{~cm}^{-1}$ band increased linearly with the amount of ammonia adsorbed at $320 \mathrm{~K}$ in Na-H13X (exchange degree 97.5\%). Infrared (I.R.) spectra were recorded at each sorption step until the $\mathrm{NaNH}_{3}$ band is absent; the slope of this line was taken as the extinction coefficient of the $1450 \mathrm{~cm}^{-1}$ band. The value of it was approximately $0.12 \mathrm{~cm}^{2}$. $\mu \mathrm{mol}^{-1}$.

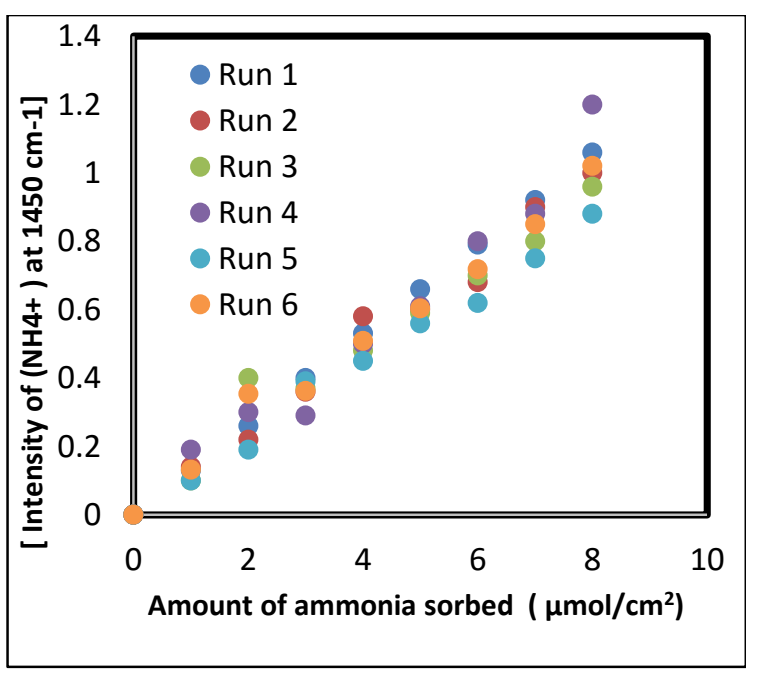

Figure (7): The relation between the intensity at $1450 \mathrm{~cm}^{-1}$ band of $\mathrm{NH}_{4}^{+}$and the amount of ammonia adsorbed in six independent experiments for $\mathrm{H}-13 \mathrm{X}$ Zeolites (exchange degree $97.5 \%$ ) at $320 \mathrm{~K}$.
The amounts of ammonia reacting with the Brønsted acid sites were calculated from the intensities of the $\mathrm{NH}_{4}^{+}$at $1450 \mathrm{~cm}^{-1}$ and the extinction coefficient of this band [8].

The amounts of ammonia reacting with Lewis acid sites equal to the subtraction of the amounts of ammonia reacted with Brønsted acid sites from the total amounts of ammonia introduced in the cell. In Figure (8), the integrated intensities of $1450 \mathrm{~cm}^{-1}$ band was noticed after chemisorbed ammonia with $\mathrm{Na}-\mathrm{H}-13 \mathrm{X}$ Zeolites samples of deferent exchange degrees, an increase of $\mathrm{Na} / \mathrm{H}$ exchange degree resulted in an increase of the intensity of the Si-OH-Al band.

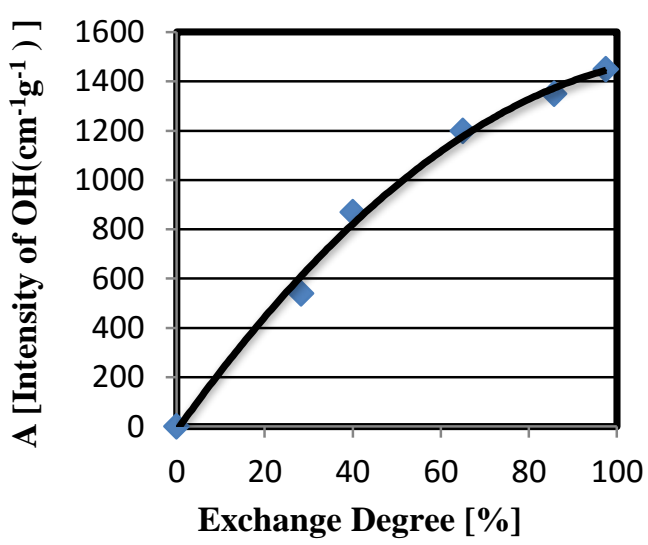

Figure (8): The integrated intensities of the of $\mathrm{OH}$ groups after ammonia adsorption in $\mathrm{Na}-\mathrm{H}-$ $13 \mathrm{X}$ Zeolites at different exchange degrees

\subsection{The concentration of $\mathrm{OH}$ in $\mathrm{Na}-\mathrm{H}-\mathrm{X}$ Zeolites}

Figures (2), (3), (4), (5) and (6) presents the spectra of $\mathrm{OH}$ groups in $\mathrm{Na}-\mathrm{H}-13 \mathrm{X}$ Zeolites measured by Fourier transformation infrared spectroscopy (FTIR) for the samples with 
different exchange degrees and after adsorption of ammonia. In Na-H-13X zeolites the presence of strong Brønsted acid sites is confirmed by IR bands in the region of frequency $3464-3441 \mathrm{~cm}^{-1}$.

Many factors influence the position of this band.

Increasing the exchange degree resulted in an increase of the intensities of the Si-OH-Al band, and resulted in a shift of the band from 3464 to $3441 \mathrm{~cm}^{-1}$. The intensity of $\mathrm{OH}$ band depends on the concentration of $\mathrm{OH}$ as well as the extinction coefficient of $\mathrm{OH}$ band [15].

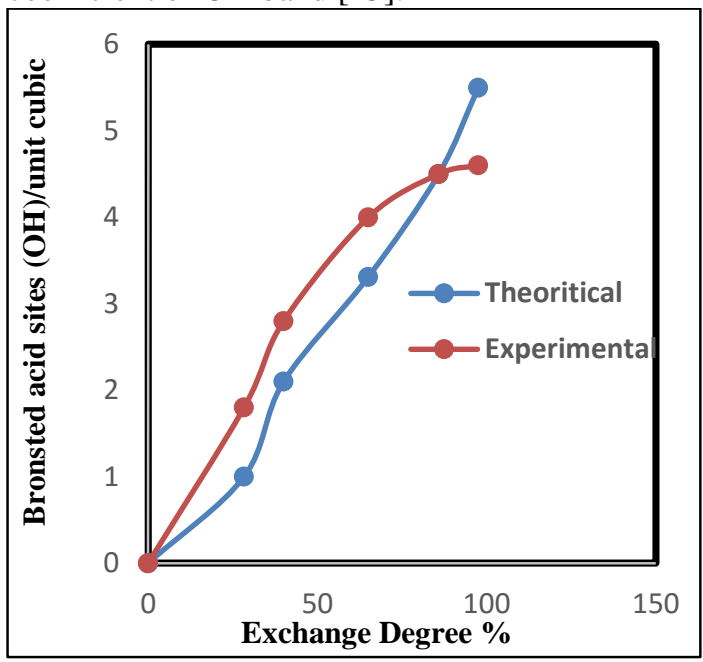

Figure (9): (a) The concentration of $\mathrm{OH}$ groups in Na-H-X Zeolites as a function of exchange degree (b) The theoretical amount of hydroxyls (amount of $\mathrm{Al}$ minus amount of $\mathrm{Na}$ )

The concentration of acidic hydroxyls in HX Zeolites was determined (in IR experiments of ammonia adsorption). The spectrum of chemisorbed ammonia showed practically only the bands of ammonia ions (at $1450 \mathrm{~cm}^{-1}$ ).

In Figures (2), (3), (4), (5) and (6) appeared one band at $1636 \mathrm{~cm}^{-1}$ which resulted from reaction of ammonia with Lewis acid sites. This band at $1636 \mathrm{~cm}^{-1}$ is very weak, that means very low concentration of Lewis acid sites in our $\mathrm{Na}-\mathrm{H}-$ 13X Zeolites samples and that is agree with the results in [5, 6, and 7]. Figure (9) presents the theoretical and experimental values of concentration of protonic sites (Si-OH-Al) for each exchange degree (the amounts of Brønsted acid sites / unit cube) in Na- H-13X-Zeolites, experimental values calculated practically from the experiments of ammonia sorption, which is not very different from the values calculated theoretically from the composition of the zeolites, the theoretical values of the concentration of protonic sites calculated from (the amounts of $\mathrm{Al}$ minus the amounts of $\mathrm{Na}$ ) [8].

The effect of exchange degrees on the acid strength of hydroxyls in Na-H-13X Zeolites was obtained after ammonia adsorption and found the relation between the stretching frequencies of $\mathrm{OH}$ groups in $\mathrm{NaH}-\mathrm{X}$ and the exchange degrees. In Figure (10) notice the stretching frequencies of $\mathrm{OH}$ groups decreases with increasing the exchange degrees. The data obtained from Figure (10) give evidence that acid strength increased with increasing the exchange degrees, the information on the acid strength in $\mathrm{Na}-\mathrm{H}-13 \mathrm{X}$ Zeolites was obtained by comparing the values of stretching frequencies and extinction coefficient of $\mathrm{OH}$ [15]. Meloni et. al. studied the characterization of the acidity by both calorimetry and IR and concluded that acid strength increased with the $\mathrm{Si} / \mathrm{Al}$ ratio [16].

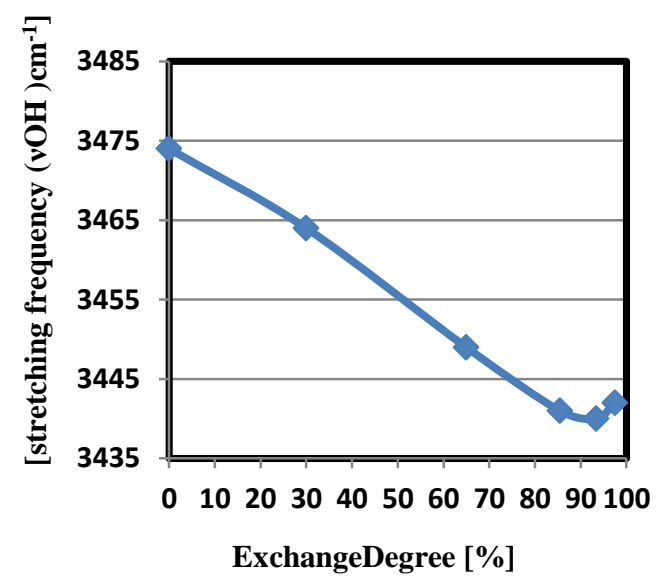

Figure (10) The stretching frequency of $\mathrm{OH}$ groups $(\mathrm{vOH}) \mathrm{cm}^{-1}$ in $\mathrm{Na}-\mathrm{H}-13 \mathrm{X}$ Zeolites as a function of $\mathrm{Na} / \mathrm{H}$ exchange degrees.

\subsection{Homogeneity of the $\mathrm{OH}$ groups in NaH-13X Zeolites}

Figure (2) shows one distinct $\mathrm{Si}-\mathrm{OH}-\mathrm{Al}$ band at $3464 \mathrm{~cm}^{-1}$, that means $\mathrm{OH}$ groups in $\mathrm{NaH}-13 \mathrm{X}$ zeolites are homogeneous and have the same geometry of all $(\mathrm{AlO})_{3} \mathrm{SiOHAl}(\mathrm{OSi})_{3}$ groups.

The spectra of $\mathrm{OH}$ groups in $\mathrm{NaH}-13 \mathrm{X}$ zeolites of different exchange degrees are presented in Figures (2), (3), (4), (5) and (6), notice the intensity of the Si-OH-Al band increase with increasing the exchange degree and also a shift of the band from 3464 to $3441 \mathrm{~cm}^{-1}$. Heterogeneity of $\mathrm{OH}$ groups in HZSM-5, Na-HX, H-Mordenite were studied by Datka ,Gil [7]. They found that all the $\mathrm{OH}$ groups were first neutralized by ammonia adsorption at $320 \mathrm{~K}$, ammonia was subsequently desorbed at vacuum by stepwise heating at increasing temperatures (480-730K) IR spectra were recorded at $320 \mathrm{~K}$ upon each desorption step. They concluded that if $\mathrm{OH}$ groups are heterogeneous, then the less acidic $\mathrm{OH}$ of the highest stretching frequency would have released ammonia at lower desorption temperature than the more acidic $\mathrm{OH}$ of lower stretching frequency. Therefore, the IR bands of $\mathrm{OH}$ groups that are restored at ammonia desorption shifts to lower frequency with the increase in desorption temperature. They found in 
H-Mordenite the heterogeneous band of restoring $\mathrm{OH}$ is shifted by $9 \mathrm{~cm}^{-1}$, but in the case of homogeneous $\mathrm{OH}$ groups in $\mathrm{NaHX}$ the shift in frequency was only $2 \mathrm{~cm}^{-1}$ [7]. The results of these experiments of ammonia sorption and desorption agree well with our conclusion that $\mathrm{Si}$ $\mathrm{OH}-\mathrm{Al}$ groups in $\mathrm{Na}-\mathrm{H}-13 \mathrm{X}$ Zeolite are homogeneous.

\section{4- Conclusions}

1-Effect of delamination on the acid properties of $\mathrm{Na}-\mathrm{H}-13 \mathrm{X}$-faujasites was studied and from the values of intensity of $\mathrm{OH}$, the extinction coefficients and frequency shifts $\Delta v=23 \mathrm{~cm}^{-1}$ of the IR spectra after ammonia adsorption are concluded that the acidity increased with increasing dealumination that agrees with the results of catalytic studies [8].

2- The intensity of $\mathrm{OH}$ band depends on the concentration of hydroxyls as well as on the extinction coefficient of $\mathrm{OH}$ band.

3 -Increasing the exchange degree results in an increase in the concentration of the protonic sites measured by $\mathrm{NH}_{3}$ sorption.

4- Our conclusion on the homogeneity of $\mathrm{OH}$ groups in NaH13X agrees with the results of Datka et al [17], [18].

\section{References}

[1] C. Otero Arean et. al, the combined use of acetonitrile and adamantane -carbonitrile as IR spectroscopic probes to discriminate between external and internal surfaces of medium pore zeolites, Journal Microporous and Mesoporous Materials , 34(2000) 55-60.

[2] Nikolay Cherkasov, Tanya Vazhnova , Dmitry B. Lukyanov, Quantitative infra-red studies of Brønsted acid sites in zeolites : Case study of the zeolite mordenite, J. Vibrational spectroscopy,83(2016)170-179.

[3] H. A. Benesi and B. H. C. Winquist: Surface Acidity of Solid Catalysts, J. Advances in catalysis , 27 (1978) 97.

[4] M. Maache, A. Janin, J.C. Lavalley, and E. Benazzi, FT infrared study of Brønsted acidity of H-mordenites : Heterogeneity and effect of delamination, J. Zeolites 15; 507-516, (1995).

[5] J. Datka and B. Gil, Heterogeneity of $\mathrm{OH}$ Groups in Faujasites studied by IR Spectroscopy, Journal of Catalysis 145,372376 (1994).

[6] J. Datka , B. Gil ,Teresa, K.G. Domagala, Homogeneous $\mathrm{OH}$ groups in dealuminated HY zeolite studied by IR spectroscopy, J. Microporous and Mesoporous Materials 47 (2001) 61-66.
[7] J. Datka , B. Gil, Heterogeneity of $\mathrm{OH}$ groups in HZSM-5 zeolites, IR studies of ammonia adsorption and desorption, Journal of Molecular Structure, 596(2001) 41-45.

[8] J. Datka , B. Gil and A. Kubacka ,Acid properties of $\mathrm{NaH}$ - mordenites : Infrared spectroscopic studies of ammonia sorption, $\mathrm{J}$. Zeolites 15;501-506,(1995).

[9]Masato Takeuchi, Tatsuya Tsukamoto, Atsushi Kondo and Masaya Matsuoka, Investigation of $\mathrm{NH}_{3}$ and $\mathrm{NH}_{4}{ }^{+}$adsorbed on ZSM-5 zeolites by near and middle infrared spectroscopy, Catalysis Science and Technology (2015),5, 4587-4593.

[10]O. Cairon , K. Thomas, A. Chambellan ,T. Chevreau, Acid - catalysed benzene hydroconversion using various zeolites : Brønsted acidity ,hydrogenation and side reactions, J. Applied Catalysis A :General 238 (2003) 167-183.

[11]M. Guisnet, P. Ayrault, J. Datka, Acid properties of mazzite zeolites studied by IR spectroscopy, J. Microporous and Mesoporous Materials 20(1997)283-291 .

[12]Shashikant A. Kadam, Mariya V. Shamzhy, IR Operando Study of Ethanol Dehydration over MFI Zeolite, Catalysis Today, Accepted Manuscript, 9-9-2017.

[13] Paola Lanzafame, Katia Barbera, Georgia, Comparison of $\mathrm{H}^{+}$and $\mathrm{NH}_{4}{ }^{+}$forms of zeolites as acid catalysts for HMF etherification, Catalysis Today, Accepted Manuscript, 2-82017.

[14] Ying Li, Qi, Sun, Shouying Huang, Zaizhe Cheng, Kai Cai, Jing Lv, Xinbin, Dimethyl ether carbonylation over pyridine - modified MOR : Enhanced stability influence by acidity, Catalysis Today, volume 311, 2018 , Pages81-88.

[15] K. Gora-Marek , J. Datka ,IR studies of OH groups in mesoporous aluminosilicates, J. Applied Catalysis A :General 302 (2006) 104109.

[16] Meloni, S. Laforge, D. Martin, M. Guisnet, E. Rombi, Solinas, Acidic and catalytic properties of H-MCM-22 zeolites, characterization of the acidity by pyridine adsorption, J. of Applied Catalysis A: General 215 (2001) 55-66.

[17] J. Datka, B. Gill, and Kubacka, Heterogeneity of $\mathrm{OH}$ groups in $\mathrm{NaH}-$ mordenites: Effect of $\mathrm{Na} / \mathrm{H}$ exchange degree, J. Zeolites 18: 245-249, 1997.

[18] J. Datka , B. Gil, P. Baran, IR Study of heterogeneity of $\mathrm{OH}$ groups in zeolite HYsplitting of $\mathrm{OH}$ and $\mathrm{OD}$ bands, Journal of Molecular Structure, 645 (2003) 45-49. 


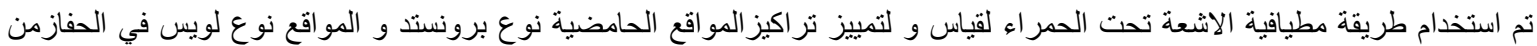

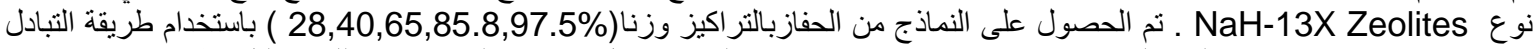

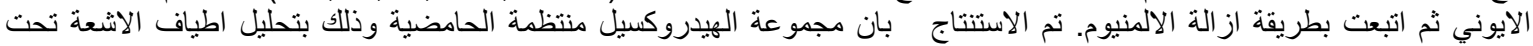

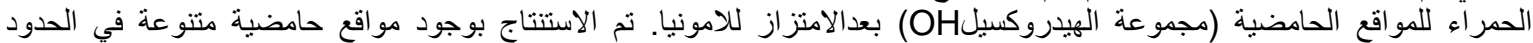

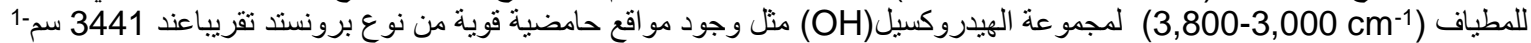

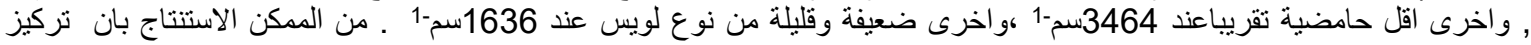

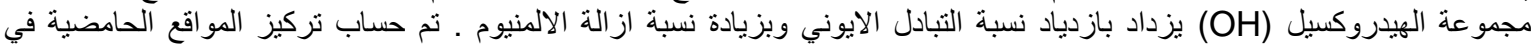

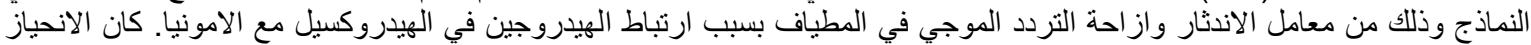

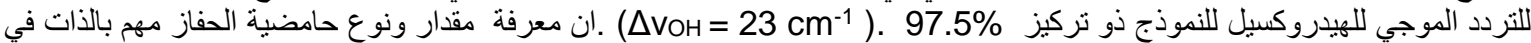
التفاعلات التي تتطلب وسطا حامضيا 